\section{Kompass \\ Neumología}

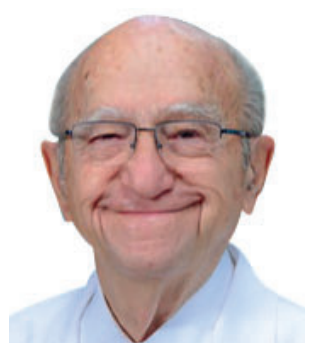

\section{León Green-Schneeweiss}

Centro Médico ABC Observatorio

Álvaro Obregón, CDMX, México

\title{
Presente y futuro del tratamiento del cáncer de pulmón
}

El cáncer de pulmón (CP) de ser un tumor raro a principios del siglo XX se ha convertido en la primera causa de muerte por cáncer a nivel mundial. A diferencia de otros tumores de los que no se conoce su etiología, en éste, se conoce perfectamente bien; es un tumor maligno autoproducido en la que intervienen varios factores en su génesis como: Tabaquismo, humo de leña, radón y contaminación atmosférica entre otros, además es causa etiológica para tumores de cavidad oral, faringe, laringe, lengua, esófago, riñón y vejiga siendo el tumor más frecuente que el cáncer de colon, próstata y mama juntos.

Desde que se desarrollan las primeras células tumorales en la mucosa del árbol traqueobronquial y/o en los alveolos periféricos hasta que el tumor se hace visible en broncoscopía o tomografía, pasan 20 a 30 años, de esta manera el escrutinio y tamizaje es un proceso de estudio sistemático y dinámico para diagnóstico temprano y oportuno de CP como lo demostró sin lugar a dudas el estudio NELSON [1-2]; realizado con tomografía computarizada (TC) de tórax de baja radiación en fumadores y exfumadores en edades de 55 a 74 años sin comorbilidades que contraindicaran cirugía y cuyo resultado demostró, una reducción de la mortalidad global y sobrevida de 20\%.

En la actualidad el manejo, diagnóstico y tratamiento integral del cáncer debe ser multimodal y multidisciplinario en el que un grupo de especialistas certificados por sus respectivos consejos, con experiencia y práctica activa con criterio unificado estudian y tratan al enfermo obteniendo así los mejores resultados.

Es indudable el avance de la ciencia y de los métodos invasivos para el diagnostico de tan letal enfermedad: sobresaliendola tomografía computarizada cuatridimensional (4DCT) la que demuestra con mayor precisión la masa tumoral a la vez que permite suministrar con mayor fidelidad, el manejo con radioterapia o broncoscopia de fluorescencia con fuente de luz filtrada de longitudes de onda alrededor de 400nm o un láser de longitud de 408 en la que se distinguen las propiedades de los fluóroforos endógenos, los cambios bioquímicos en el colágeno y la elastina y el estado metabólico NADH y flavinas de la mucosa bronquial o utilizando luz azul centrada en 415nmy luz verde en 540nm técnica denominada «lmagen de banda estrecha» logrando analizar la vasculatura bronquial (mucosa y submucosa) e identificar los patrones aberrantes y finalmente la biopsia guiada por broncoscopía y navegación electromagnética.

De todos es sabido que el diagnostico temprano permite un mejor tratamiento, una sobrevida mas amplia y con mejor calidad de vida de esta manera la etapificacion sugerida de TNM en su octava edición de la neoplasia es indispensable para determinar con precisión la conducta a seguir.
En el estudio del espécimen es conveniente se identifiquen las alteraciones genéticas existente como mutaciones, translocaciones que permiten diseñar una terapia mas adecuada y mas personal. Los genes mas alterados incluyen EGFR, KRAS, ALK, ROS, ERB2, BRAF, MET base la clasificacio molecular con objetivos especificos en el manejo, mas ambas clasificaciones no se contraponen por el contrario enrriquecen el panorama del tratamiento.

La resección quirúrgica y en especial la lobectomía es el procedimiento de elección para curar el CP; la resección debe ser con un margen de 1-2 cm. de tejido sano incluyendo los ganglios de drenaje en bloque y en una sola pieza, marcar con clips metálicos el sitio de resección de los ganglios así como áreas sospechosas en el parénquima vecino pero, por desgracia en México (como en muchas partes del mundo) los mas de los enfermos diagnosticados o internados en servicios especializados llegan en los estadios avanzados III-IV y fuera de tratamiento quirúrgico $[3,4]$.

Los avances en equipos de broncoscopía, instrumental quirúrgico, cirugía toracoscópica asistida por video, robótica, radioterapia (de intensidad modulada) estereotáctica corporal, ablación por radiofrecuencia, laser endobronquial, quimioterapia blanco, (identificación de mutaciones con factor pronostico como EGFR y ALK y desarrollo de moléculas que actúen específicamente en genes mutados) e inmunoterapia entre information@karger.com

() 2020 S. Karger GmbH, Freiburg

www.karger.com $/ \mathrm{kxn}$

Karger
Dr. León Green-Schneeweis

Centro Médico ABC Observatorio, Consultorio 315

Torre Sur 136, No. 116

01120 Álvaro Obregón, CDMX, México

leongreens@hotmail.com 
otras, con indicaciones cada vez más precisas en aplicación neoadyuvante, adyuvante, secuencial o concomitante permiten tratamiento más preciso y efectivo con mayores posibilidades de curación y menos efectos colaterales; también están indicadas como tratamiento paliativo para pacientes con tumores avanzados.

\section{Referencias}

1 van Klaveren RJ, Oudkerk M, Prokop M, et al. Management of lung nodules detected by volume CT scanning. N Engl. J Med. 2009; 361(23):2221-2229.
El problema futuro es sombrío e inclusive impresionante ya que se menciona que en caso de no encontrar nuevas medidas de tratamiento especifico la mortalidad mundial seguirá creciendo en formas por demás importante. De esta manera debemos de centrarnos principalmente en el diagnostico temprano utilizando el armamen-

2 Ru Zhao Y, Xie X, de Koning HJ, et al.: NELSON lung cancer screening study. Cancer Imaging. 2011;11 Spec No A(1A):S79-S84.

3 Detterbeck FC, Boffa DJ, Kim AW, et al.: The Eight Edition Lung Cancer Stage classification. Chest. 2017;151(1):193-203. tario tecnológico con el que contamos hoy en dia pero, lo mas importantes es utilizar campañas de difusión masivas sobre la mejor forma de conservar la salud respiratoria evitando los factores de riesgo ampliamente conocidos.

Dr. León Green-Schneeweiss

4 Huber RM, de Ruysscher D, Hoffman H, et al.: Interdisciplinary Multimodality Management of stage III nonsmall cell lung cancer. Eur Resp Rev. 2019;28(152):1-13. 